\title{
Personal epistemologies and social representations : And how
} pÿthey meet in people s conceptions of the origin of human species

\section{Pirttilä-Backman, Anna-Maija}

Routledge

2020

Pirttilä-Backman , A-M , Ahola , S \& Sakki , I 2020 , Personal epistemologies and social

pÿrepresentations : And how they meet in people s conceptions of the origin of human species

. in E K Kallio (ed.) , Development of Adult Thinking : Interdisciplinary Perspectives on

Cognitive Development and Adult Learning . Routledge , Abingdon, Oxon , pp. 47-62 . https://doi.org/10.4324/97813

http://hdl.handle.net/10138/334850

https://doi.org/10.4324/9781315187464-4

unspecified

acceptedVersion

Downloaded from Helda, University of Helsinki institutional repository.

This is an electronic reprint of the original article.

This reprint may differ from the original in pagination and typographic detail.

Please cite the original version. 
Anna-Maija Pirttilä-Backman, Salla Ahola \& Inari Sakki

\title{
Personal epistemologies and social representations - and how they meet in people's conceptions of the origin of human species ${ }^{1}$
}

\begin{abstract}
This chapter examines human thinking from two different perspectives: personal epistemologies and social representations. We first present a developmental model of personal epistemologies, that is, individuals' assumptions of the nature of knowledge and justification of knowledge claims. After that we introduce the theory of social representations - how people as groups form everyday theories of issues that are interesting, important or new to them. The specific focus of this chapter is on how Finnish people form everyday understandings of the human species within the frameworks of evolution theory and creation story - both having a relatively strong position within the Finnish educational system and culture. People's understanding of the origins of human beings are analysed from the perspectives of personal epistemologies and social representations. The results show that knowledge is polymorphic and social subjects may use contrasting modes of reasoning depending on the context and their needs. We suggest that the concept of cognitive polyphasia helps understand the use of different, sometimes contradictory explanatory models in people's everyday thinking of human species. We conclude by discussing the potential of combining personal epistemologies and social representations in the study of human thinking.
\end{abstract}

Whose claims about climate change should one believe? What is the most effective way to defend against economic crises? Which is healthier, butter or margarine? Newspapers and magazines write about these kinds of topics on a regular basis, they are disputed in current affairs and argued in peer groups, homes, workplaces and more widely on the internet. How do individuals, groups and societies react and get along amidst contradictory and changing information? Does new research provide adequate grounds for understanding these issues? Or is the information flow a threat under which people feel powerless, become indifferent and withdraw themselves?

What conceptions of knowledge do people have and how do they justify their knowledge claims and how do these change? In this chapter we present one of the better-known developmental models of these issues, namely that of Karen Kitchener (1978) and Patricia King (1977), constructed in the 1970s in their doctoral dissertations. Initially they used the title Reflective Judgment Model. They adopted the concept from the century-old texts of John Dewey, in which he deliberated on juridical decision making: the decisions were important, they had important practical consequences for those concerned, and they should not be made arbitrarily. King (1977) and Kitchener (1978) remarked that Dewey did not clarify how the decisions should be made; however, he talked about the 
selection of the circumstances that should be taken into account and the need to evaluate the validity and applicability of evidence in the situation at hand - about reflective judgment. In Kitchener's and King's terminology, reflective judgment refers to the most developed way to deal with problems, to which there is no single and unequivocally correct solution. Their developmental model describes the move towards this highest stage.

Since then, the term "personal epistemologies" has been introduced as a distinction to the epistemologies presented by professional philosophies (see e.g. Hofer \& Pintrich, 1997; Pintrich, 2002). The term also suits the model of Kitchener and King well, because it describes and explains the development of assumptions of what knowledge is and the ways how knowledge claims are justified. In this chapter, we first discuss personal epistemologies and their manifestations among adults, as well as their practical significance and relationship to wisdom research. After that, we shift the perspective onto groups and communities and their formation of shared everyday knowledge, i.e. social representations. Finally, we make an excursion to people's understanding of the origins of human beings and analyse these conceptions from the perspectives of personal epistemologies and social representations. This example comes from Finnish interviews, from a North European country with highly educated population.

\section{The development of personal epistemologies}

The questions raised at the beginning of this chapter were of the type that also concerned Kitchener and King in the 1970s. They wanted to find out how people deal with ill-structured (called also wicked) problems that do not have one obvious solution. For the most part, Kitchener's and King's research was based on the pioneering work of William Perry (1970) on what he called the intellectual and ethical development of Harvard students (see Seppälä, Kallio \& Lindblom-Ylänne, chapter 3, this volume).

The key question of Kitchener's and King's dissertations was whether thinking concerning knowledge would actually develop further than what Perry described in his model at stages 1-6 (see Seppälä et al., this volume). Together they developed a method for studying personal epistemologies. Kitchener's special research question was to find out how personal epistemologies differ from verbal reasoning and fluency, while King focused on differences from logical reasoning. According to their results, the evolution of personal epistemologies could not be reduced to either 
logical reasoning or verbal reasoning or fluency, even though some connections between them were found.

Perry's (1970) interview method, starting from questions that were topical to the interviewees, had produced a good description of the personal epistemologies up to a certain point, as the questions related to knowledge were topical to the students at the beginning and intermediate stages of their studies. However, at the end of the studies, questions related to personal life choices were more pressing than issues related to knowing, and Perry's last positions reflected this. Kitchener and King specifically asked whether there was epistemic development after the knowing-related positions Perry had described. They ended up presenting their interviewees with dilemmas that were constructed of contradictory claims. They sought their interviewees' standpoints to the dilemmas and how they justified their views. In this way, the researchers were able to concentrate on knowing-related issues. Their final series included dilemmas covering questions in four different areas of life (construction of the Egyptian pyramids, the objectivity of news reporting, the effect of food additives on health, and the origin of the human species). In the dilemmas, both of the contrasting standpoints were presented as having previously been supported, for example, in the discussion of food additives like this:

"There have been frequent reports about the relationship between chemicals that are added to foods and the safety of these foods. Some studies indicate that such chemicals can cause cancer, making these foods unsafe to eat. Other studies, however, show that chemical additives are not harmful, and actually make the foods containing them more safe to eat." (King \& Kitchener, 1994, p. 260)

After the presentation of each dilemma, the interviewees were asked for their standpoints, followed by a number of more detailed and deepening questions such as how they ended up adopting this position and could they ever think differently. If an interviewee said that s/he was unable to take a stand, s/he was asked why this was not possible and whether s/he could ever take a stand on the matter and if so, under what conditions. Further clarifications were requested if an interviewee used words like "theory" or "proof" without further characterisation. The interviewees in King's and Kitchener's PhD dissertations were junior high school students and graduate and postgraduate students in liberal arts. 
Kitchener and King presented a seven-stage developmental model of assumptions of knowledge and justifications of knowledge claims (see Table 1).

\section{TABLE 1 HERE}

Understandings of knowledge evolve from absolutistic, concrete understanding towards conceiving knowledge as hypothetical constructions. Critical milestones in this development are the gradually deepening understanding of uncertainty and contextuality as well as the realisation of the possibility to compare different knowledge claims on the basis of negotiable and justified criteria.

Kitchener's and King's work belongs to the group of cognitive-developmental models and theories. Its roots can be found in the theories of Piaget (see Seppälä et al., this volume), Lawrence Kohlberg (see Juujärvi \& Helkama, as well as Mäkiniemi \& Vainio, chapters 5 and 6, this volume) and William Perry (see Seppälä et al., this volume). More specifically, it belongs to the subgroup of complex stage models as defined by James Rest (1979). In these models the conceptions and justifications are reorganised during each new stage relative to the previous one. The changes are qualitative transformations in the assumptions and justifications of knowledge, not just linear increases or decreases in some assumptions. Furthermore, it is assumed and also well documented that people's thinking and arguing can have features not only from one stage, but also from several successive stages at the same time. ${ }^{2}$ Typically, the developmental models of personal epistemologies have presented a similar line of development as Kitchener's and King's model, though there is variation in the number of stages or levels across models (see, e.g., Hofer, 2016).

A number of Finnish studies that have used Kitchener's and King's method (e.g., Kajanne, 2003; Pirttilä-Backman, 1993; Pirttilä-Backman \& Kajanne, 2001) have convincingly demonstrated the connection between educational levels and also educational fields and such factors as diversity of living environments, work experience and role-playing opportunities - and the developmental stages of personal epistemologies. Pirttilä-Backman (1993) has also demonstrated that the model is not bound to any single theory of truth. Thoughts reflecting critical realism, pragmatism, and relativism can be categorised into the highest stage as long as they are sufficiently well-founded. (For further critical analysis of assumptions in the adult developmental theories, see Tuominen \& Kallio, chapter 13, this volume.)

In the aforementioned Finnish studies (e.g., Pirttilä-Backman, 1993), the interviewees argued in ways that reflected mostly the same stages regardless of the subject matter of the dilemma. This means that the assumptions about knowledge were similar regardless of the substance of the 
question. Furthermore, the interviewees' own field (i.e. engineering, medicine or social sciences) did not have a differentiating effect on the argumentation across dilemmas. Also, King's and Kitchener's (2004) respondents argued rather similarly about various dilemmas, although the consistency in the US studies has been weaker than in the aforementioned systematically heterogeneous Finnish sample (which consisted of interviewees representing several fields, and both students and those already in working life).

More recently however, researchers have increasingly started to consider that people's conceptions of knowledge could differ depending on the domain, context, academic discipline, school subject, or different areas of life (Greene, Sandoval \& Bråten, 2016; Hofer, 2006; Muis, Bendixen \& Haerle, 2006; Pintrich, 2002). Indeed, the current models are increasingly taking such domain-specific and contextual aspects of knowledge-related thinking into account (Greene et al., 2016).

\section{The significance of personal epistemologies in everyday life}

What is the role of personal epistemologies in practice? Several studies have found that they are associated with recognising different views, argumentation and drawing conclusions. More specifically, they are related, for example, to the ability to recognise contrasting views and to evaluate them (Mason \& Boscolo, 2004), skills of argumentation on climate change and genetically modified food (Mason \& Scirica, 2006), the ability to recognise reasoning fallacies (Weinstock, Neuman \& Glassner, 2006), as well as views on food additives (Kajanne, 2003) and evolution acceptance (Borgerding, Deniz \& Anderson, 2017). Recently Staerklé and Green (2014) suggested that personal epistemologies could also contribute to defining intergroup relations.

Other people's personal epistemologies can also have a significant role in making important decisions that concern a particular individual, for example, in contexts such as law (Weinstock, 2016) or medicine (Eastwood et al., 2017). Anyone who ends up on trial or in an equivalent situation, where other people give verdicts or make other important decisions, would probably hope that the decision-makers have personal epistemologies that are as advanced as possible. Less ideal would be that important decisions are made by people who do not want to go to any further effort after finding a solution that seems plausible or who think it is not worthwhile to deliberate and to scrutinise different opinions that seem like knowledge but are not finally backed up by any proper evidence (Weinstock \& Cronin, 2003). Similar concerns have been raised recently in discussions 
about the so-called post-truth age, and unfortunately, there are many recent examples particularly from public decision-making in which this ideal has not been met.

\section{Social representations: Everyday, common-sense theories of groups}

When an individual knows something, personal epistemologies provide the framework to it, even though people seldom think about these frames consciously. Knowledge can mean an absolute truth, an opinion or a well-formulated hypothetical construction to a person. People form their own personal epistemologies and personal standpoints in social interaction, and they also form ideas and build knowledge as groups and communities.

The theory of social representations (SRT) is the most notable approach from which to study groups and communities' shared understandings. The seminal work in the field, Serge Moscovici's (1961/2008) dissertation La psychanalyse, son image et son public is about how psychoanalysis spread to French society - how it was addressed in newspapers representing various ideological trends and how it was rooted in French daily conversations. The liberal, the communist and the catholic press - the French opinion leaders at that time - presented and discussed psychoanalysis from their own premises, raised and faded out themes according to their own interests, and adjusted concepts and presented them in the light of their own starting points. Moscovici suggested that new things are made familiar and understandable through two processes. In anchoring, something new and unknown is associated with already known phenomena and located in existing conceptual matrixes. For example, a psychoanalytic therapy session is seen as a catholic confession, whereby it becomes understandable. The second process is objectification, in which an abstract case gets almost a concrete manifestation. For example, when god is perceived to be a father, the experience is almost physically touchable.

Durkheim's concept of collective representations provided one theoretical point of reference to the theory of social representations: while Durkheim's collective representations are permanent and unchanging, explanatory and given, social representations are dynamic and something to be explained (Moscovici, 1981). Also, the impact of Piaget on Moscovici's work was profound. Although Moscovici abandoned Piaget's description of human development as being an evolutionary, linear process, he retained the idea of cooperative interaction in the development of knowledge as well as the creative aspect of representation, meaning that in gaining new knowledge, children must reinvent the world since they often have no familiar foundations for those aspects of 
their environment that they are confronting for the first time (Sakki, Menard \& Pirttilä-Backman, 2017; Jovchelovich, 2007).

According to Moscovici (1973, p. xiii), social representations are "systems of values, ideas and practices with a twofold function; first, to establish an order which will enable individuals to orient themselves in their material and social world and to master it; secondly, to enable communication to take place among the members of a community by providing them with a code for social exchange and a code for naming and classifying unambiguously the various aspects of their world and their individual and group history." These representations are the counterparts of our society to myths and belief systems of traditional communities. They are not just about "opinions" or "images of something" or "attitudes towards something" but "theories" or "areas of knowledge" as their own entities and with their own legitimacy. With the formation of common everyday theories, abstract and unknown things become familiar and communicable.

More recently the concept of cognitive polyphasia has gained a lot of interest. The idea of cognitive polyphasia had already been proposed in 1961 by Moscovici when he defined it as "dynamic coexistence - interference and specialization - of distinct modalities of knowledge that correspond to definite relationships of man and his environment" (Moscovici, 2008, p. 190). Thus, the concept helps us understand knowledge as a plurality of parallel and sometimes contradictory forms of thought, meanings, and practices that reside in the same individual, group, or community (Jovchelovitch, 2007; Wagner, Duveen, Verma \& Themel, 2000) and fulfils a variety of functions and responds to different needs of social life (Jovchelovitch, 2008). It means that representations may be heterogeneous and contradictory, and under certain circumstances, they can occur at the same time and in the same situation (Jovchelovitch, 2007; Provencher, 2011).

In this line of thought, in a more recent discussion on cognitive polyphasia, Moscovici (Moscovici \& Markova, 2000) emphasises the role of norms, context and goals in knowledge construction. While norms provide limits to what is considered as rational thinking and knowledge in our societies, the context guides the way people recognise and process information and goals shape the way people use such knowledge (Provencher, 2011). In other words, cognitive polyphasia is an asset of human cognition, a tool that enables adjustment to different situations and conditions (e.g., Renedo \& Jovchelovitch, 2007; Caillaud \& Kalampalikis, 2013), the expression of multiple identities (Howarth, Wagner, Magnusson \& Sammut, 2014; Amer, Howarth \& Ragini, 2015) as well as the communication between representations in the maintenance or transformation of knowledge (Jovchelovitch, 2008). 
A concept tightly related to the cognitive polyphasia is the one of themata (Vignaux \& Moscovici, 1994), which refers to the centrality of interdependent antinomies, for example, human/nature or tradition/modern, and thus, to polyphasia in the process of social representation (Markova, 2003). In practice, this means that people draw upon oppositional representations in their construction of knowledge (e.g., Renedo \& Jovchelovitch, 2007; Wagner et al., 2000). In line with such a perspective, it also means that social representational processes are linked to power. Through communication and dialogue, some representations gain more success and become self-evident at the expense of other representations of more marginalised groups in society (O'Dwyer, Lyons \& Cohrs, 2016; Howarth, 2006).

Importantly, thus, in comparison with theories based on the cognitive-developmental paradigm presented above, in the social representations theory (SRT) the knowledge about certain objects is not considered as a developmental process that transforms from one representation to another; instead different forms of knowledge co-exist, contradict and constantly change (Jovchelovitch, 2007; 2008).

\section{How personal epistemologies and social representations help us understand how people make sense of the origin of their species}

People have long been fascinated by their own origins, for which various cultures have offered a wide range of explanations during history. Next, we will discuss Finns' understandings of the origin of human beings and what role personal epistemologies and social representations have in these understandings. Evolution theory has a strong position in Finland as an explanation of human origins. It is taught in schools as part of life sciences. Some of its elements are well rooted in people's minds, as manifested in everyday jokes about the cousins in zoos and in the well-known dialogue in Väinö Linna’s (1954/2015) seminal novel Unknown Soldiers, in which soldiers chat, reflect and joke about human prehistory and the place of fish in it. The creation story as an explanation of the origin of human beings has an even longer history than the theory of evolution. Also, it still has a significant place in the worldview of the majority of the population. The creation story of human history, however, can be interpreted in quite different ways. For example, Niiniluoto (1984) has argued that even educated people at the end of the 19th century could literally rely on the creation story as a prehistory of humankind, but today, according to the position prevailing within the Lutheran Church, Finland's majority church, the story of creation must be understood 
symbolically. However, there is still more variety in the standpoints among the population, as becomes evident below.

At the practical level, science and religion are intertwined in many ways. For example, in Finland, the Lutheran priests receive their education in theological faculties, even though the church ordains the priests. The inauguration programme for the academic year of the largest university in Finland continues to include a worship service. In schools, ethics as an alternative to religion is still an exception to the mainstream. Learning outcomes in religion are rated as in any other school subject. Many Finns get married and buried according to church ceremonies, and relatives and friends not belonging to church customarily participate in these events.

One dilemma of Kitchener and King dealt with the question of human origins. It was presented to Finnish interviewees as a part of a broader project (Pirttilä-Backman, 1993). The dilemma that also covers ontological assumptions says:

"Many religions of the world have creation stories. These stories suggest that a divine being created the earth and its people. Scientists claim, however, that people evolved from lower animal forms (some of which were similar to apes) into the human forms we know today." (King \& Kitchener, 1994, p. 260)

In Finland, 142 people responded to all four of Kitchener's and King's dilemmas (Pirttilä-Backman, 1993). The respondents represented different educational levels and fields and included both students in halfway of their studies and graduates from the same educational institutions ten years earlier as well as people with little specialised education.

The interview protocol for each dilemma received first three scores according to Kitchener's and King's scoring manual ${ }^{3}$, reflecting the development stages manifested in the interviews (see Table 1 for the stage descriptions). For example, if during the interview views and justifications reflecting only stage 3 were presented, the scorer recorded 333. On the other hand, if the majority of the arguments corresponded to stage six, but there were also clear indications of stage 5 and some of stage 4, a score of 654 was assigned. Next, an average of each dilemma was calculated for each interviewee, after which a personal stage average was formed by calculating the average of all dilemmas except the one concerning human origins. The distribution of these personal averages based on three dilemmas are shown in Table 2. 


\section{TABLE 2 HERE}

Table 2 shows that the most common development stage average was around four, while the next typical averages were five and three. The highest stages were rather exceptional. This has been the case also in studies conducted in the U.S., with the stage averages varying from 3.6 among high school students to 5.3 among doctoral students (King, Kitchener \& Wood, 1994). ${ }^{4}$

In the dilemma of human pre-history, evolution was chosen by $46 \%$ of women, and $65 \%$ of men. Creation was selected by $20 \%$ of women and $12.5 \%$ of men, while $13 \%$ of women and $12.5 \%$ of men chose both standpoints. For the rest, $21 \%$ of women and $10 \%$ of men did not take a stand on this dilemma. Although there was some degree of variation in percentages, the difference between the genders in the basic standpoints was not statistically significant.

The interviewees with the highest stage scores had all chosen the theory of evolution. A considerable proportion of the interviewees who had low stage scores had also come to this solution. Those who had selected evolution had a clearly larger deviation in the mean stage scores than other groups. Looking at Group-wise scores, the highest mean stage score (4.7) was in the group that had selected both evolution and creation. The mean score for those who had selected evolution was 4.3 and for those who had selected creation it was 3.8. The differences in group-wise mean stage scores proved statistically significant between those who had selected both standpoints and those who had selected creation only; there were no significant differences between the other groups.

Those who chose evolution justified their view by arguing that there is evidence, knowledge and proof of evolution. According to the justifications of the statements and their meanings, these interviewees could still be divided into two subgroups. In the first of these, the proof of evolutionary theory was what was known at the moment, while other topics were hardly taken up. This subgroup was categorised as "There is evidence of evolution, but not about the other option". In the second subgroup, "I'm so realistic that I have never believed in the supernatural", evidence and facts were considered to be the sole property of reality and the basis for the solutions, because supernatural reality was regarded as non-existent.

Also those who chose creation as their only standpoint expressed their choice clearly. They could be divided into the following four subgroups on the basis of their main justifications: 1) I believe; 2) This is what I learnt, and this is how it may be; 3) But where did everything begin from? 4) But we are not monkeys. 
Those who chose both standpoints considered that there is no contradiction between evolution and creation. The view was clarified in four different ways that can be summarised as follows: 1) It is the same thing expressed in different ways; 2) Both can be true because neither of them can be said to be wrong; 3) Evolution is certain but religion also has its place; and 4) Someone created lower forms of animals, which then developed into higher animal forms.

Those who did not take any stand formed the fourth major class. Each interview had been started by asking for the standpoint. If the interviewee did not choose either of the options presented, later in the interview s/he was asked, inter alia, why the interviewee could not or was not willing to take a stand and whether s/he could at some point and on some premises choose a standpoint. Therefore, in these interviews, the interviewees presented different views on the origin of human beings. Two clear subgroups emerged from this group: 1) This is unknown; and 2) I have not yet solved this for myself. For more details of the qualitative analysis and results, see Pirttilä-Backman and Hakanen, (1994).

\section{Conclusions: Social representations and personal epistemologies in making sense of the human origin}

In Finland, the evolution theory and the story of creation are both well-known explanations for the origin of human beings. They constitute thus a largely shared, common information base that people and groups can use when forming and maintaining their own standpoints on the issue. All the interviewees had at least heard about both standpoints, but they used them differently to form their individual standpoints and came to different solutions.

Fish and monkeys were in people's talk the major milestones in the evolution theory. Concrete images of the theory of evolution, objectifications, have thus been formed through them. Animals were also used as anchors for making the scientific theory more familiar. Relevant to the interviewees was also that evolution was a scientific theory; scholarship convinced them, even though the scientific details were not necessarily very clear to them.

The strong position of science in our culture is also reflected in that all the interviewees who had received the highest stage ratings had chosen evolution. The highest developmental stages of personal epistemologies are in line with the scientific worldview. However, the greatest variation in developmental stages was among those who had chosen evolution, which means that some members of this group scored very low in developmental stages. One explanation for this - as well 
as for those who had chosen creation and had low average stage scores - is these interviewees' difficulty in considering multiple viewpoints simultaneously. An interesting single observation in the study was that those who chose both evolution and creation were also rated with higher average developmental stages. This finding is in line with the hypothesis of cognitive polyphasia discussed above (Moscovici, 1961/2008), indicating that contrasting modes of reasoning can be found coexisting without any tension, even in the same individual. On the contrary, rather than being mutually exclusive, conflicting themes can operate as an asset from which people can draw the resources to deal with in their social life (Renedo \& Jovchelovitch, 2007).

Even though evolution as a scientific theory provided assurance for many, it also caused resistance. To some, accepting evolution would have meant betraying their faith. Creation could be seen as part of faith as such, related to the Creator. Religion as such could be seen as bringing safety and feelings of togetherness. However, strictness and rigidity and use of power were also connected to it. (Pirttilä-Backman \& Hakanen, 1994)

As has been outlined by Moscovici (Moscovici \& Markova, 2000), norms provide boundaries for what is considered to be knowledge in certain social groups, thus people may rely on models of explanation that gain broad social acceptance within their social group despite contradictory evidence. Also, in line with the hypothesis of cognitive polyphasia (Moscovici, 1961/2008), knowledge is polymorphic and social subjects may use it in a heuristic manner depending on the context and their needs.

There are several "everyday theories" in Finland about the origin of human beings. It is possible that those who have chosen creation as their only standpoint are more likely than others to form cohesive groups, because they hold a minority standpoint in a society governed by a scientific worldview. These people as a group may also have most clearly formulated everyday theory of the topic, even though it would not technically correspond the highest stages of personal epistemologies. On average, representatives of the other standpoints do not necessarily have an equally strong need to discuss their choice. Concerning the simultaneous examination of personal epistemologies and social representations, it would be interesting to focus on different communities in which one of the key premises in the group formation is the human origin standpoint.

Even though the connections between personal epistemologies and social representations have not yet been studied extensively, as seen above, personal epistemologies are interestingly linked to the common everyday theories we construct of different types of new, complex and important issues. On the one hand, we are attached to our groups and communities by these everyday theories. They 
are an important part of our living environments. We can thus ask whether the everyday theories facilitate or hinder communication with others and facing complex issues. On the other hand, it is equally important to examine if the personal epistemologies of the people support the diverse use of cultural information and different explanation models or if they constrain the positions that can be formed.

Further attention is also needed to understand better the interplay between cognitive polyphasia, personal epistemologies and wisdom. In their recent study, Manwaring and colleagues (2018) found that among religious people in the United States, religiosity was positively associated with creationistic views and negatively with acceptance of evolution. However, ability in scientific reasoning did not predict acceptance of evolution among these people. Neither was the acceptance of evolution indicative of high scientific reasoning ability. As a response to the call by Manwaring and colleagues for better understanding the barriers in accepting the evolution theory, the different belief systems could be analysed from the perspective of cognitive polyphasia, which provides a wide framework to analyse the phenomenon simultaneously at both societal and individual levels.

More developed epistemic understanding has already been related to wisdom (for recent reviews of the concept of wisdom, see Grossmann, 2017; Walsh, 2015). The ability to understand the uncertainties related to knowing and the ability to make sound judgements in the face of this uncertainty, have been a part of many definitions of wisdom (Kitchener \& Brenner, 1990). These judgements are related to difficult real-life problems to which there are no clear answers. Haste, Markoulis and Helkama (1998) and Murray (2010) have also suggested that one of the aspects of wisdom would concern understanding the nature and the boundaries of knowledge. Therefore, understanding the development of personal epistemologies can be useful in understanding wisdom in particular Stages 4 to 7 in Kitchener's and King's model, because they all involve the acknowledgement of the uncertainty of knowing (Kitchener \& Brenner, 1990). However, the elements that can be used to characterise wisdom are not present until Stage 7: the ability to integrate opposing views and to make reasoned judgements while recognising the limitations and uncertainties present in all knowing, including one's personal limits (Kitchener \& Brenner, 1990). The analysis presented in this chapter of the relationship between personal epistemologies and social representations has provided new insights to understanding people's thinking about human origins. In a similar way, future research on the relationship between cognitive polyphasia and wisdom may bring new insights to both fields. 


\section{References}

Amer, A., Howarth, C. \& Sen, R. (2015). Diasporic virginities: social representations of virginity and identity formation amongst British Arab Muslim women. Culture and Psychology, 21, 3-19.

Borgerding, L. A., Deniz, H. \& Anderson, E. S. (2017). Evolution acceptance and epistemological beliefs of college biology students. Journal of Research in Science Teaching, 54(4), 493-519.

Caillaud, S. \& Kalampalikis, N. (2013). Focus groups and ecological practices: a psychosocial approach. Qualitative Research in Psychology, 10, 382-401.

Eastwood, J. L., Koppelman-White, E., Mi, M., Wasserman, J. A., Krug III, E. F. \& Joyce, B. (2017). Epistemic cognition in medical education: a literature review. International Journal of Medical Education, 8, 1-12.

Greene, J. A., Sandoval, W. A. \& Bråten, I. (2016). Reflections and future directions. In J. A. Greene, W. A. Sandoval \& I. Bråten (Eds.), Handbook of epistemic cognition (pp. 495-510). New York, NY: Routledge.

Grossmann, I. (2017). Wisdom in context. Perspectives on Psychological Science, 12(2), 233-257.

Haste, H., Markoulis, D. \& Helkama, K. (1998). Morality, wisdom and the life-span. In A. Demetriou, W. Doise \& C. F. M. van Lieshout (Eds.), Life-span developmental psychology (pp. 317-350). Chichester: John Wiley \& Sons.

Hofer, B. K. (2016). Epistemic cognition as a psychological construct. Advancements and challenges. In J. A. Greene, W. A. Sandoval \& I. Bråten (Eds.), Handbook of epistemic cognition (pp. 19-38). New York, NY: Routledge.

Hofer, B. K. (2006). Beliefs about knowledge and knowing: Integrating domain specificity and domain generality: A response to Muis, Bendixen, and Haerle. Educational Psychology Review, $18(1), 67-76$.

Hofer, B. K. \& Pintrich, P. R. (1997). The development of epistemological theories:

Beliefs about knowledge and knowing and their relation to learning. Review of Educational Research, 67(1), 88-140.

Howarth, C. (2006). A social representation is not a quiet thing: exploring the critical potential of social representations theory. British Journal of Social Psychology, 45, 65-86. 
Howarth, C., Wagner, W., Magnusson, N. \& Sammut, G. (2014). "It's only other people who make me feel black": acculturation, identity and agency in a multicultural community. Political Psychology, 35, 81-95.

Jovchelovitch, S. (2007). Knowledge in context. Representations, community and culture. Cambridge: Routledge.

Jovchelovitch, S. (2008). Rehabilitation of common sense: social representations, science and cognitive polyphasia. Journal for the Theory of Social Behaviour, 38, 431-449.

Kajanne, A. (2003). Structure and content: The relationship between reflective judgment and laypeople's viewpoints. Journal of Adult Development, 10(3), 173-188.

King, P. M. (1977). The development of reflective judgment and formal operational thinking in adolescents and young adults. Unpublished doctoral thesis. University of Minnesota.

King, P. M. \& Kitchener, K. S. (1994). Developing Reflective Judgment: Understanding and promoting intellectual growth and critical thinking in adolescent and adults. San Francisco, CA: Jossey-Bass.

King, P. M. \& Kitchener, K. S. (2004). Reflective Judgment: Theory and research on the development of epistemic assumptions through adulthood. Educational Psychologist, 39(1), 5-18.

King, P. M., Kitchener, K. S. \& Wood, P. K. (1994). Research on the reflective judgment model. In P. M. King \& K. S. Kitchener (Eds.), Developing Reflective Judgment: Understanding and promoting intellectual growth and critical thinking in adolescent and adults (pp. 124-188). San Francisco, CA: Jossey-Bass.

Kitchener, K. S. (1978). Intellectual development in late adolescents and young adults: reflective judgment and verbal reasoning. Unpublished doctoral thesis. University of Minnesota.

Kitchener, K. S. \& Brenner, H. G. (1990). Wisdom and reflective judgment: knowing in the face of uncertainty. In R. J. Sternberg (Ed.), Wisdom. Its nature, origins, and development (pp. 212-229). Cambridge: Cambridge University Press,

Linna, V. (2015). Unkown soldiers (L. Yamaguchi, Trans.). Penguin Classics. (Original work published 1954). 
Manwaring, K. F., Jensen, J. L., Gill, R. A., Sudweeks, R. R., Davies, R. S. \& Bybee, S. M. (2018). Scientific reasoning ability does not predict scientific views on evolution among religious individuals. Evolution: Education and Outreach, 11(1), 2.

Marková, I. (2003). Dialogicality and social representations. Cambridge: Cambridge University Press.

Mason, L. \& Boscolo, P. (2004). Role of epistemological understanding and interest in interpreting a controversy and in topic-specific belief change. Contemporary Educational Psychology, 29(2), $103-128$.

Mason, L. \& Scirica, F. (2006). Prediction of students' argumentation skills about controversial topics by epistemological understanding. Learning and Instruction, 16(5), 492-509.

Moscovici, S. (2008). Psychoanalysis: Its image and its public (D. Masey, Trans.) Cambridge: Polity. (Original work published 1961).

Moscovici, S. (1973). Foreword. In C. Hertzlich (Ed.), Health and illness: A social psychological analysis (pp. ix-xiv). European Monographs in Social Psychology 5. London: Academic Press.

Moscovici, S. (1981). On social representations. In J. P. Forgas (Ed.), Social cognition. Perspectives on everyday understanding (pp. 181-209). London: Academic Press.

Moscovici, S. \& Marková, I. (2000). Ideas and their development: A dialogue between Serge Moscovici and Ivana Marková. In Moscovici, S. Social representations. Cambridge: Polity.

Muis, K. R., Bendixen, L. D. \& Haerle, F. C. (2006). Domain-generality and domain-specificity in personal epistemology research: Philosophical and empirical reflections in the development of a theoretical framework. Educational Psychology Review, 18(1), 3-54.

Murray, T. (2010). Exploring epistemic wisdom: Ethical and practical implications of integral studies and methodological pluralism for collaboration and knowledge-building. In S. EsbjörnHargens (Ed.), Integral theory in action: Applied, theoretical, and constructive perspectives on the AQAL model (pp. 345-367). New York, NY: State University of New York Press.

Niiniluoto, I. (1984). Tiede, filosofia ja maailmankatsomus: Filosofisia esseitä tiedosta ja sen arvosta [Science, philosophy and worldview: Philosophical essays on knowledge and its value]. Helsinki: Otava. 
O'Dwyer, E., Lyons, E. \& Cohrs, C. (2016). How Irish citizens negotiate foreign policy: a social representations approach to neutrality. Political Psychology, 37, 165-181.

Perry, W. G. Jr. (1970). Forms of intellectual and ethical development in the college years: A scheme. New York, NY: Holt, Rinehart \& Winston.

Pintrich, P. R. (2002). Future challenges and directions for theory and research on personal epistemology. In B. K. Hofer \& P. R. Pintrich (Eds.), Personal epistemology: The psychology of beliefs about knowledge and knowing (pp. 389-414). Mahwah, NJ: Lawrence Erlbaum.

Pirttilä-Backman, A.-M. (1993). The social psychology of knowledge reassessed: Toward a new delineation of the field with empirical substantiation. Helsinki: Finnish Academy of Science and Letters.

Pirttilä-Backman, A-M. \& Ahola, S. (2016). Henkilökohtaiset tietokäsitykset ja yhteiset arkiteoriat [Personal epistemologies and common everyday theories]. In E. Kallio (Ed.), Ajattelun kehitys aikuisuudessa [The development of thinking in adulthood] (pp. 135-153). Research in Educational Sciences Publication Series; No. 71. Jyväskylä: The Finnish Educational Research Association.

Pirttilä-Backman, A.-M. \& Hakanen, H. (1994). Luomiskertomus ja evoluutio nykysuomalaisen maailmankuvan elementteinä [Creation story and evolution as elements in the worldview of contemporary Finns]. In A.-M. Pirttilä-Backman \& K. M. Vesala (Eds.), Kognitiosta maailmankuvan ulottuvuuksiin [From cognition to the dimensions of worldview] (pp. 39-83). University of Helsinki, Department of Social Psychology, Research, 2.

Pirttilä-Backman, A.-M \& Kajanne, A. (2001). The development of implicit epistemologies during early and middle adulthood. Journal of Adult Development 8(2), 81-97.

Provencher, C. (2011). Towards a better understanding of cognitive polyphasia. Journal for the Theory of Social Behaviour, 41, 377-395.

Renedo, A. \& Jovchelovitch, S. (2007). Expert knowledge, cognitive polyphasia and health: A study on social representations of homelessness among professionals working in the voluntary sector in London. Journal of Health Psychology, 12, 779-790.

Rest, J. R. (1979). Development in judging moral issues. Minneapolis, MN: University of Minnesota Press. 
Sakki, I., Menard, R. \& Pirttilä-Backman, A-M. (2017). Sosiaaliset representaatiot - mielen ja yhteiskunnan välinen silta [Social representations - Bridging between mind and society]. In A. Gronow \& T. Kaidesoja (Eds.), Sosiaalinen mieli [Human social mind] (pp. 104-129). Helsinki: Gaudeamus.

Staerklé, C \& Green, E. (2014). Ryhmäkeskeisyydestä moniarvoisuuteen: ryhmienvälinen reflektiivinen tieto [From rroup-centrism to pluralism: An intergroup approach to reflexive knowledge]. In L. Myyry, S. Ahola, M. Ahokas \& I. Sakki (Eds.), Arkiajattelu, tieto ja oikeudenmukaisuus [Everyday thinking, knowledge and justice] (pp. 92-110). University of Helsinki: Publications of the Department of Social Research, 18.

Vignaux, G. \& Moscovici, S. (1994). Le concept de themata [The concept of themata]. In C. Guimelli (Ed.), Structures et transformations des representations sociales [Structures and transformations of social representations], (pp. 25-72). Neuchatel: Delachaux et Niestle.

Wagner, W., Duveen, G., Verma, J. \& Themel, M. (2000). 'I have some faith and at the same time I don't believe' - Cognitive polyphasia and cultural change in India. Journal of Community and Applied Social Psychology, 10, 301-314.

Walsh, R. (2015). What is wisdom? Cross-cultural and cross-disciplinary syntheses. Review of General Psychology, 19(3), 278-293.

Weinstock, M. (2016). Epistemic cognition in legal reasoning. In J. A. Greene, W. A. Sandoval \& I. Bråten (Eds.), Handbook of epistemic cognition (pp. 215-229). New York, NY: Routledge.

Weinstock, M. \& Cronin, M. A. (2003). The everyday production of knowledge: Individual differences in epistemological understanding and juror-reasoning skill. Applied Cognitive Psychology 17(2), 161-181.

Weinstock, M. P., Neuman, Y. \& Glassner, A. (2006). Identification of informal reasoning fallacies as a function of epistemological level, grade level, and cognitive ability. Journal of Educational Psychology 98(2), 327-341.

\footnotetext{
${ }^{1}$ An earlier and more limited version of this chapter has been presented in Finnish in PirttiläBackman and Ahola (2016). The major difference between these two chapters is in the concept of cognitive polyphasia that is discussed in the current chapter and used in the interpretation of the results.

${ }^{2}$ See Pirttilä-Backman (1993) for different types of typical and atypical stage patterns.
} 


\footnotetext{
${ }^{3}$ Neither the interviewers nor the scorers of this study have gone through the certification procedures developed by Karen Kitchener and Patricia King. See Pirttilä-Backman (1993) and Pirttilä-Backman \& Kajanne (2001) for the safeguards used to ensure the quality of the interviews and scoring.

${ }^{4}$ Detailed information on the mean stages among interviewees representing different fields and levels of education, as well as among current students and those who had graduated ten years ago can be found in Pirttilä-Backman (1993), and longitudinal results can be found in Pirttilä-Backman and Kajanne (2001).
}

Table 1. King's and Kitchener's (e.g. 1994) developmental model of personal epistemologies.

\begin{tabular}{|c|c|c|}
\hline Stage & $\begin{array}{l}\text { Assumptions of } \\
\text { knowledge }\end{array}$ & Justifications \\
\hline 1 & $\begin{array}{l}\text { Absolute equivalence exists between } \\
\text { what is seen and what is: what I see is } \\
\text { true. }\end{array}$ & $\begin{array}{l}\text { Because knowing is just seeing, } \\
\text { justifications are not needed. }\end{array}$ \\
\hline 2 & $\begin{array}{l}\text { There is right and wrong knowledge - } \\
\text { and somebody always knows the truth. } \\
\text { Uncertainty does not exist. }\end{array}$ & $\begin{array}{l}\text { Facts can be known by one's own } \\
\text { observation. If they cannot be directly } \\
\text { known, one can appeal to the } \\
\text { authorities. }\end{array}$ \\
\hline 3 & $\begin{array}{l}\text { Not even authorities always know the } \\
\text { truth, but uncertain claims are temporary } \\
\text { - the absolute truth can be found. }\end{array}$ & $\begin{array}{l}\text { In uncertain matters beliefs can be } \\
\text { justified by what feels right or what } \\
\text { one wants to believe. }\end{array}$ \\
\hline 4 & $\begin{array}{l}\text { Knowledge per se is uncertain and } \\
\text { idiosyncratic. So, uncertainty is a } \\
\text { permanent and acceptable condition. }\end{array}$ & $\begin{array}{l}\text { The reasons for uncertainty are } \\
\text { concrete. Beliefs and feelings can be } \\
\text { used as justifications. }\end{array}$ \\
\hline 5 & $\begin{array}{l}\text { Knowledge is always contextual, and } \\
\text { beliefs can be justified only in a } \\
\text { particular context, as things are }\end{array}$ & $\begin{array}{l}\text { The justifications of beliefs can be } \\
\text { evaluated only within one context. } \\
\text { However, the arguments can still be }\end{array}$ \\
\hline
\end{tabular}


interpreted differently in different frameworks.

6 Despite the contextuality of knowledge, some beliefs can be regarded as being better than others. This is based on the ability to make comparisons between reference frames. Research is a process that results in changes in knowledge.

7
Knowledge is a result of critical combination and evaluation of standpoints and evidence. Some estimates, interpretations and solutions can therefore be more justified than others. However, the current knowledge will be re-evaluated later. This means that with time, current knowledge will most probably change into newer versions. evaluated by looking at the relative merit of their various components.

Different beliefs can be compared with each other justifiably.

Evaluation and comparison are continuing processes in which new viewpoints can come up. Also, new criteria can be brought into consideration. 
Table 2. The distribution of interviewees' personal stage averages of three dilemmas $(\mathrm{N}=142$; source: Pirttilä-Backman \& Hakanen, 1994).

\begin{tabular}{ll}
\hline $\begin{array}{ll}\text { Stage mean of } \\
\text { three dilemmas }\end{array}$ & Percentage of \\
\hline less than 3.49 & $22.5 \%$ \\
\hline $3.5-4.49$ & $41.5 \%$ \\
\hline $4.5-5.49$ & $23.9 \%$ \\
& \\
$5.5-6.49$ & $9.2 \%$ \\
$6.5-7$ & $2.8 \%$ \\
\hline
\end{tabular}

